\title{
Unsolved questions in prophylactic tricuspid valve repair and the possible role of transcatheter tricuspid intervention
}

\author{
Ana Paula Tagliari ${ }^{1}$, Diego Vilela Santos ${ }^{2}$, Eduardo Keller Saadi $^{3}$, Maurizio Taramasso ${ }^{4}$, \\ and carlos mestres ${ }^{1}$ \\ ${ }^{1}$ University Hospital Zurich \\ ${ }^{2}$ Incor - Instituto do Coração de Natal \\ ${ }^{3}$ Hospital São Lucas da Pontifícia Universidade Católica do Rio Grande do Sul \\ ${ }^{4}$ UniversityHospital Zurich
}

May 11, 2020

\begin{abstract}
Tricuspid regurgitation progression after left-sided surgery and its correlation with worse postoperative and long-term outcomes is a highly debated topic. Some studies support prophylactic tricuspid repair based on annulus dimension rather than on tricuspid regurgitation severity only, while others are in favor of more conservative management. Furthermore, the advent of percutaneous tricuspid valve intervention and its promising short-term outcomes has introduced a new factor to be taken into account on the tricuspid intervention decision-making process. We present a review on prophylactic tricuspid valve intervention, covering currently available data, as well as the role of transcatheter tricuspid valve intervention in this equation.
\end{abstract}

\section{Abbreviations:}

Functional tricuspid regurgitation (FTR); mitral valve (MV); tricuspid regurgitation (TR); tricuspid valve (TV); transcatheter tricuspid valve intervention (TTVI); transesophageal echocardiogram (TEE); transthoracic echocardiography (TTE).

\section{Introduction}

The presence of some degree of tricuspid regurgitation (TR) can be considered the most common valvular heart disease, affecting $65-85 \%$ of the population ${ }^{1}$. If considered only significant TR (moderate or severe), the condition is estimated to affect up to 1.6 million individuals in the United States ${ }^{2}$, with secondary or functional tricuspid regurgitation (FTR) being responsible for almost $90 \%$ of the cases $^{3}$.

Despite this prevalence, TR was during many years a forgotten and underappreciated disease ${ }^{4,5}$. One of the reasons behind TR undertreatment was the concept, postulated by Braunwald in $1967^{6}$ that functional tricuspid regurgitation (FTR) would improve or disappear once the primary left-sided problem was treated. Another reason was the high surgical mortality rate associated with isolated tricuspid valve (TV) intervention, which, unfortunately, remains at least partially correct, since TR carries an impactful surgical mortality $(8.8 \%$ $-9.7 \%)^{7}$. However, such high mortality is in part biased by the advanced stage that patients are referred to surgery, with severe right ventricle dysfunction and end-organ damage ${ }^{8}$.

Additionally, several publications have demonstrated that up to $74 \%$ of patients submitted to a successful mitral valve repair will exhibit significant tricuspid regurgitation (TR) over more than 3-year follow-up ${ }^{9}$, and one half will progress by more than two grades in a mean follow-up of 4.8 years ${ }^{10}$. It is also remarkable that, while isolated TV surgery due to residual TR after mitral valve (MV) intervention is associated with high mortality and poor outcomes ${ }^{11,7}$, concomitant TV repair does not increase the operative mortality ${ }^{10,12}$. 
Based on these arguments and on the fact that FTR is associated with biventricular dysfunction, poor quality of life and, ultimately, death ${ }^{13-15}$, a more aggressive TR surgical approach was suggested. Hence, the concept of treating TR based on tricuspid annulus diameter rather than TR severity was raised ${ }^{10}$.

\section{Prophylactic tricuspid intervention}

Carpentier was one of the first authors to recommend tricuspid annular dilation as a more objective parameter to indicate TV repair. His evaluation method consisted in TV surgical exploration, checking the annulus ability to admit three fingerbreadths of the surgeon's hand, in which case TV repair would be indicated ${ }^{16}$.

Three decades later, Dreyfus et al. evaluated tricuspid annuloplasty performed concomitantly with MV surgery in the presence of intraoperative tricuspid annular diameter [?] $70 \mathrm{~mm}$, measured from the anteroseptal commissure to the anteroposterior commissure, regardless the preoperative TR grade. In a 5-year follow-up, TR degree, as well as patients' functional status, was significantly lower in the TV treated group ${ }^{10}$.

Regarding echocardiographic measurement, evaluating 50 patients submitted to MV replacement due to rheumatic disease, Colombo et at. suggested that tricuspid annulus diameter $>21 \mathrm{~mm} / \mathrm{m}^{2}$ could be a reliable parameter to indicate concomitant TV repair in this specific patient population ${ }^{17}$.

Similarly, using a tricuspid annulus dimension [?] 40mm $\left(>21 \mathrm{~mm} / \mathrm{m}^{2}\right)$ measured preoperatively in transthoracic echocardiography (TTE) 4-chamber view as a cut-off to indicate concomitant TR intervention, Van deVeire et al. demonstrated better reverse right ventricular remodeling and less postoperative TR prevalence, when compared with isolated MV surgery ${ }^{18}$. Figure 1 illustrates echocardiographic tricuspid valve evaluation, and Figure 2 a TR surgical repair using an annuloplasty ring.

In 2012, Benedetto et al. conducted a randomized trial enrolling 44 patients with less-than-severe TR $([?]+2)$ and annular dilatation ([?] 40mm) treated at the same time that MV surgery. Early results demonstrated the safety of the combined approach (1 case of 30-day mortality in each group), with just a discreet increase in cardiopulmonary bypass and aortic cross-clamping time. After 12 months, those patients who underwent TV intervention presented with significant TR reduction (TR absent in $71 \%$ vs. $19 \%$; $\mathrm{p}=0.001)$, improvement in functional capacity ( 6 min walking test: $+115 \pm 23 \mathrm{~m}$ vs. $+75 \pm 35 \mathrm{~m} ; \mathrm{p}=0.008)$, and right ventricular reverse remodeling [right ventricle long-axis $71 \pm 7 \mathrm{~mm}$ preoperative vs. $65 \pm 8 \mathrm{~mm}$ postoperative $(\mathrm{p}<0.01)$ and short-axis $33 \pm 4 \mathrm{~mm}$ preoperative vs. $27 \pm 5 \mathrm{~mm}$ postoperative $(\mathrm{p}=0.01)$ in $\mathrm{TV}$ treated group; right ventricle long-axis $72 \pm 6 \mathrm{~mm}$ preoperative vs. $70 \pm 7 \mathrm{~mm}$ postoperative $(\mathrm{p}=0.08)$, and short-axis $34 \pm 5 \mathrm{~mm}$ preoperative vs. $33 \pm 5 \mathrm{~mm}$ postoperative $(\mathrm{p}=0.1)$ in TV non-treated group $]^{19}$.

Two-years after this publication, Chikwe et al. tested the association of an aggressive concomitant prophylactic TV repair (annular dilatation [?] 40mm or [?] moderate TR) in patients undergoing MV repair for degenerative diseases. No increased 30-day mortality and morbidity, lower TR progression rate, reduced pulmonary hypertension and improvement in induced right ventricle recovery were observed at 7-year follow-up ${ }^{20}$.

Regarding guideline recommendations, the American Heart Association/American College of Cardiology and the European Society of Cardiology/European Association for Cardio-Thoracic Surgery have recommended TR repair concomitant with left-sided surgery in the presence of annular size [?] $40 \mathrm{~mm}\left(>21 \mathrm{~mm} / \mathrm{m}^{2}\right)$, regardless of TR degree, as a Class IIa of recommendation ${ }^{21,22}$, which still means a low level of evidence.

\section{Controversial information}

Despite the accumulated information reported, recent articles have presented opposite results. In a singlecenter retrospective cohort of 312 patients undergoing MV repair for degenerative diseases, David et al. demonstrated no association between tricuspid annulus size and subsequent FTR development, with a low rate of postoperative TR (at 7 years follow-up) in patients presenting annulus size $<40 \mathrm{~mm}(6.8 \%, 95 \%$ CI 4.6\%. $-10.4 \%)$, but also in those with annulus [?] 40mm $(6.0 \%, 95 \% \text { CI } 2.9 \%-12.2 \%)^{23}$. The limitation of this study is that tricuspid annular size was measured intraoperatively, using transesophageal echocardiogram (TEE) under general anesthesia, while the current guidelines are based on TTE or direct intraoperative 
measurement. Regardless this limitation, TR prevalence was similar to that previously described by Rajbanshi et al., in whose study only $6 \%$ of patients developed severe TR at 5-year follow-up after MV repair or replacement ${ }^{24}$.

Furthermore, no advantage in terms of TV reoperation rate (HR 0.46;95\% CI $0.10-2.07 ; \mathrm{p}=0.31$ ); congestive heart failure (HR 1.12; 95\% CI $0.37-3.36 ; \mathrm{p}=0.84$ ); and death (HR 1.41; 95\% CI $0.82-2.42 ; \mathrm{p}=0.22$ ) when mild-to-moderate FTR was concomitantly managed was suggested by Ro et al. ${ }^{25}$.

In terms of possible disadvantages of combined procedures, although prophylactic TV repair has not been associated with increased mortality rate, some authors have suggested association with longer operative times $^{26}$, higher pacemaker rates ${ }^{27}$ and longer hospital length of stay ${ }^{28}$.

Additional data comes from the results of a single-center prospective randomized trial published in 2019. In this study, prophylactic tricuspid annuloplasty performed concomitantly to MV repair in patients with less-than-severe FTR was able to reduce FTR recurrence, but did not affect functional capacity or right ventricular remodeling. Five-year freedom from cardiac-related mortality was similar in TV treated and non-treated patients $(94.1+-3.2 \% \text { in treated-group vs. } 89.7+-4.3 \% \text { in TV non-treated; } \mathrm{p}=0.9)^{29}$.

When this new study was included in a meta-analysis, however, the conclusions went in the opposite direction. TV repair was associated with lower cardiovascular mortality, all-cause mortality and TR progression over a median of 5.3 years of follow-up (cardiovascular mortality: RR $0.46,95 \%$ CI $0.28-0.75 ; \mathrm{p}=0.002$; all-cause mortality: RR 0.68, 95\% CI 0.49 - 0.96; $\mathrm{p}=0.03$; TR progression: RR $0.26,95 \%$ CI $0.12-0.56$; $\mathrm{p}<0.001)^{30}$. Likewise, when the prevalence of TR after MV repair due to leaflet prolapse at a more extended follow-up are evaluated, even David et al. showed numbers that are more concerned. A $20.8 \%$ probability of persistent or new moderate or severe TR at 20 years made the author point that maybe a much longer follow-up that those previously reported is needed to observe changes in tricuspid annulus diameter ${ }^{31}$.

\section{Transcatheter tricuspid valve intervention}

transcatheter tricuspid valve intervention (TTVI) has emerged as an attractive alternative approach for inoperable or high surgical risk candidates (STS-PROM $>8 \%)^{32}$ who cannot be submitted to a conventional open cardiac surgery.

Current available devices are designed for different anatomical and functional purposes, as follow (adapted from Curio J et al. and Kolte D et al.) $)^{33,34}$ :

1) Leaflet approximation or coaptation [MitraClip in the Tricuspid Position (Figure 3) or TriClip (Abbott Vascular, Santa Clara, CA, USA), Pascal system (Edwards Lifesciences Corp, Irvine, CA, USA), TriCinch ${ }^{\text {TM }}$ Coil System (4Tech Cardio, Galway, Ireland), Forma ${ }^{\text {TM }}$ Repair System (Edwards Lifesciences)];

2) Annuloplasty [Cardioband(r) Tricuspid Repair System (Edwards Lifesciences), IRIS Transcatheter Annuloplasty Ring (Millipede Inc, Santa Rosa, CA, USA), Trialign device (Mitralign Inc., Tewksbury, Mass., USA)];

3) Orthotopic [GATE ${ }^{\mathrm{TM}}$ system self-expanding bioprosthesis (NaviGate Cardiac Structures, Lake Forest, CA, USA)] or heterotopic [Heterotopic caval valve implantation using the SAPIEN (Edwards Lifesciences Corp, Irvine, CA, USA), or the TricValve(r) (P\&F Products GmbH, Vienna, Austria) systems].

In TTVI trials, technical feasibility and safety was proven, and TTVI showed a low periprocedural mortality $(30 \text {-day mortality }=3.6 \%)^{35}$, even when performed in high-surgical risk patients. Nonetheless, Taramasso et al. recently suggested an important benefit in terms of survival and rehospitalization rates when TTVI was compared with medical therapy [1-year mortality: $23+-3 \%$ vs $36+-3 \%$ in TTVI versus control group, respectively; $\mathrm{p}=0.001$ ); 1 -year rehospitalization: $26+-3 \%$ vs $47+-3 \%$, in TTVI versus control group, respectively; $\mathrm{p}<0.0001)^{36}$.

\section{Current Questions}

Considering the information presented above, the following are meant to be discussion points: 
1. Because TV annulus dilation as predictor of TR progression and criteria to indicate concomitant surgery is, still nowadays, controversial, is there a significant benefit of unrestricted prophylactic TV intervention? Or a watch-and-wait strategy with subsequent intervention, if necessary, could be a valuable alternative in some subgroup of patients? What patients' profile could benefit from a more conservative strategy?

2. Once one of the reasons to indicate concomitant TV repair is the assumption that a future reoperation would be associated with high surgical risk and poor outcomes, in a hypothetical scenario of TTVI providing significant lower procedural mortality, should this argument be reviewed?

3. If the indication of tricuspid prophylactic intervention based on annulus dilation is valid, should also TTVI be indicated in symptomatic, high-risk patients, based in annular dilation ([?] $40 \mathrm{~mm})$ rather than TR grade?

\section{Conclusion}

The comments in this document do not presume of answering the questions presented above, but to introduce in debate new issues, in order to stimulate a more in-depth discussion.

Tricuspid annular dilatation seems to play an important role as predictor of early and late outcomes after left-sided surgery, especially if other parameter such as leaflet coaptation and tethering are also present. However, controversial data regarding the role of prophylactic tricuspid valve repair concomitant with leftsided intervention make this procedure not as widespread as it could be. Nonetheless, with the advent of percutaneous tricuspid valve interventions, it turned into an interesting alternative approach in selected patients.

The decision-making process should be based on individual factors such as patient desire, clinical symptoms, response to medical management, quality of life, and life expectancy, as well as tricuspid valve morphology, currently available devices and procedural risks.

\section{References}

1. Singh JP, Evans JC, Levy D, Larson MG, Freed LA, Fuller DL, et al. Prevalence and clinical determinants of mitral, tricuspid, and aortic regurgitation (the Framingham Heart Study). Am J Cardiol 1999;83:897-902.

2. Stuge O, Liddicoat J. Emerging opportunities for cardiac surgeons within structural heart disease. J Thorac Cardiovasc Surg 2006;132:1258-61.

3. Badano LP, Muraru D, Enriquez-Sarano M. Assessment of functional tricuspid regurgitation. Eur Heart J 2013;34:1875-85.

4. Stephens EH, Borger MA. "Forgotten" valve or "enigmatic" valve? Further insights into the tricuspid valve in patients undergoing mitral valve surgery. J Thorac Cardiovasc Surg 2014; 148:1962-1964.

5. Lentini S. Surgery for rheumatic mitral valve disease and the forgotten role of concomitant organic tricuspid valve impairment. Heart 2013; 99:145.

6. Braunwald NS, Ross J Jr, Morrow AG. Conservative management of tricuspid regurgitation in patients undergoing mitral valve replacement. Circulation 1967; 35(4, Suppl): I63-I69.

7. Zack CJ, Fender EA, Chandrashekar P, Reddy YNV, Bennett CE, Stulak JM, et al. National trends and outcomes in isolated tricuspid valve surgery. J Am Coll Cardiol 2017; 70:2953-60.

8. Tagliari AP, Taramasso M. Transcatheter tricuspid interventions: time to re-think guidelines? Aging (Albany NY) 2020; 12:1037-1038.

9. Katsi V, Raftopoulos L, Aggeli C, Vlasseros I, Felekos I, Tousoulis D, et al. Tricuspid regurgitation after successful mitral valve surgery. Interact Cardiovasc Thorac Surg 2012; 15:102-8.

10. Dreyfus GD, Corbi PJ, Chan KM, Bahrami T. Secondary tricuspid regurgitation or dilatation: Which should be the criteria for surgical repair? Ann Thorac Surg 2005; 79:127-32.

11. Kilic A, Saha-Chaudhuri P, Rankin JS, Conte JV. Trends and outcomes of tricuspid valve surgery in North America: an analysis of more than 50,000 patients from the Society of Thoracic Surgeons database. Ann Thorac Surg 2013; 96:1546-52. 
12. Vahanian A, Alfieri O, Andreotti F, Antunes MJ, Baron-Esquivias G, Baumgartner H, et al., ESC Committee for Practice Guidelines (CPG); Joint Task Force on the Management of Valvular Heart Disease of the European Society of Cardiology (ESC); European Association for Cardio-Thoracic Surgery (EACTS). Guidelines on the management of valvular heart disease (version 2012): The Joint Task Force on the Management of Valvular Heart Disease of the European Society of Cardiology (ESC) and the European Association for Cardio-Thoracic Surgery (EACTS). Eur J Cardiothorac Surg 2012; 42:S1-44.

13. Nath J, Foster E, Heidenreich PA. Impact of tricuspid regurgitation on long-term survival. J Am Coll Cardiol 2004; 43:405-409.

14. Topilsky Y, Nkomo VT, Vatury O, Michelena HI, Letourneau T, Suri RM, et al. Clinical outcome of isolated tricuspid regurgitation. JACC Cardiovasc Imaging 2014; 7:1185-94.

15. Topilsky Y, Inojosa JM, Benfari G, Vaturi O, Maltais S, Michelena H, et al. Clinical presentation and outcome of tricuspid regurgitation in patients with systolic dysfunction. Eur Heart J 2018; 39:35843592 .

16. Carpentier A, Deloche A, Dauptain J, Soyer R, Blondeau P, Piwnica A, et al. A new reconstructive operation for correction of mitral and tricuspid insufficiency. J Thorac Cardiovasc Surg 1971; 61:1-13.

17. Colombo T, Russo C, Ciliberto GR, Lanfranconi M, Bruschi G, Agati S, et al.Tricuspid regurgitation secondary to mitral valve disease: tricuspid annulus function as guide to tricuspid valve repair. Cardiovasc Surg. 2001; 9:369-77.

18. Van de Veire NR, Braun J, Delgado V, Versteegh MI, Dion RA, Klautz RJ, et al. Tricuspid annuloplasty prevents right ventricular dilatation and progression of tricuspid regurgitation in patients with tricuspid anular dilatation undergoing mitral valve repair. J Thorac Cardiovasc Surg 2011; 141:1431-9.

19. Benedetto U, Melina G, Angeloni E, Refice S, Roscitano A, Comito C, et al. Prophylactic tricuspid annuloplasty in patients with dilated tricuspid annulus undergoing mitral valve surgery. $\mathrm{J}$ Thorac Cardiovasc Surg 2012; 143:632-8.

20. Chikwe J, Itagaki S, Anyanwu A, Adams DH. Impact of Concomitant Tricuspid Annuloplasty on Tricuspid Regurgitation, Right Ventricular Function, and Pulmonary Artery Hypertension After Repair of Mitral Valve Prolapse. J Am Coll Cardiol 2015; 65:1931-8.

21. Falk V, Baumgartner H, Bax JJ, De Bonis M, Hamm C, Holm PJ, et al; ESC Scientific Document Group. 2017 ESC/EACTS Guidelines for the management of valvular heart disease. Eur J Cardiothorac Surg 2017; 52:616-64.

22. Nishimura RA, Otto CM, Bonow RO, Carabello BA, Erwin JP III, Guyton RA, et al; ACC/AHA Task Force Members. 2014 AHA/ACC guideline for the management of patients with valvular heart disease: executive summary: a report of the American College of Cardiology/American Heart Association task force on practice guidelines. Circulation 2014; 129:2440-92.

23. David TE, David CM, Manlhiot C. Tricuspid annulus diameter does not predict the development of tricuspid regurgitation after mitral valve repair for mitral regurgitation due to degenerative diseases. J Thorac Cardiovasc Surg 2018; 155:2429-36.

24. Rajbanshi BG, Suri RM, Nkomo VT, Dearani JA, Daly RC, Burkhart HM, et al. Influence of mitral valve repair versus replacement on the development of late functional tricuspid regurgitation. J Thorac Cardiovasc Surg 2014; 148:1957-62.

25. Ro SK, Kim JB, Jung SH, Choo SJ, Chung CH, Lee JW. Mild-to-moderate functional tricuspid regurgitation in patients undergoing mitral valve surgery. J Thorac Cardiovasc Surg 2013; 146:1092-7.

26. Zhu TY, Wang JG, Meng X. Does concomitant tricuspid annuloplasty increase perioperative mortality and morbidity when correcting left-sided valve disease? Interact Cardiovasc Thorac Surg 2015; 20:114-8.

27. Kilic A, Szeto WY, Atluri P, Acker MA, Hargrove WC. Operative Outcomes of Concomitant Minimally Invasive Mitral and Tricuspid Valve Surgery. Innovations (Phila) 2019; 14:412-418.

28. LaPar DJ, Mulloy DP, Stone ML, Crosby IK, Lau CL, Kron IL, et al. Concomitant tricuspid valve operations affect outcomes after mitral operations: a multiinstitutional, statewide analysis. Ann Thorac Surg 2012; 94:52-7. 
29. Pettinari M, De Kerchove L, Lazam S, Pasquet A, Gerber B, Vanoverschelde JL, et al. Mid-term results of a randomized trial of tricuspid annuloplasty for less-than-severe functional tricuspid regurgitation at the time of mitral valve surgery. Eur J Cardiothorac Surg 2019; 55:851-858.

30. Cao JY, Wales KM, Zhao DF, Seco M, Celermajer DS, Bannon PG. Repair of Less Than Severe Tricuspid Regurgitation during Left Sided Valve Surgery: A Meta-Analysis, Ann Thorac Surg 2020; 109:950-958.

31. David TE, David CM, Tsang W, Lafreniere-Roula M, Manlhiot C. Long-Term Results of Mitral Valve Repair for Regurgitation Due to Leaflet Prolapse. J Am Coll Cardiol. 2019; 74:1044-1053.

32. Voigtlander L, Seiffert M. Expanding TAVI to Low and Intermediate Risk Patients. Front Cardiovasc Med 2018; 5:92.

33. Curio J, Demir OM, Pagnesi M, Mangieri A, Giannini F, Weisz G, et al. Update on the Current Landscape of Transcatheter Options for Tricuspid Regurgitation Treatment. Interv Cardiol. 2019; 14:54-61.

34. Kolte D, Elmariah S. Current state of transcatheter tricuspid valve repair. Cardiovasc Diagn Ther 2020;10:89-97.

35. Taramasso M, Alessandrini H, Latib A, Asami M, Attinger-Toller A, Biasco L, et al. Outcomes After Current Transcatheter Tricuspid Valve Intervention: Mid-Term Results from the International TriValve Registry. JACC Cardiovasc Interv 2019; 12:155-165.

36. Taramasso M, Benfari G, van der Bijl P, Alessandrini H, Attinger-TolleA, Biasco L, et al. Transcatheter versus medical treatment of symptomatic severe tricuspid regurgitation. Am Coll Cardiol 2019; 74:2998-3008.

lsout

\section{Legend of Figures:}

Figure 1: Echocardiographic tricuspid valve evaluation.

Figure 2: Tricuspid valve ring annuloplasty technique.

Figure 3: Tricuspid valve percutaneous repair using the MitraClip system. A. Preoperative tricuspid regurgitation. B. Intraprocedural Clip positioning between the anterior and the septal tricuspid leaflets. C. Tricuspid regurgitation after Clip implantation.
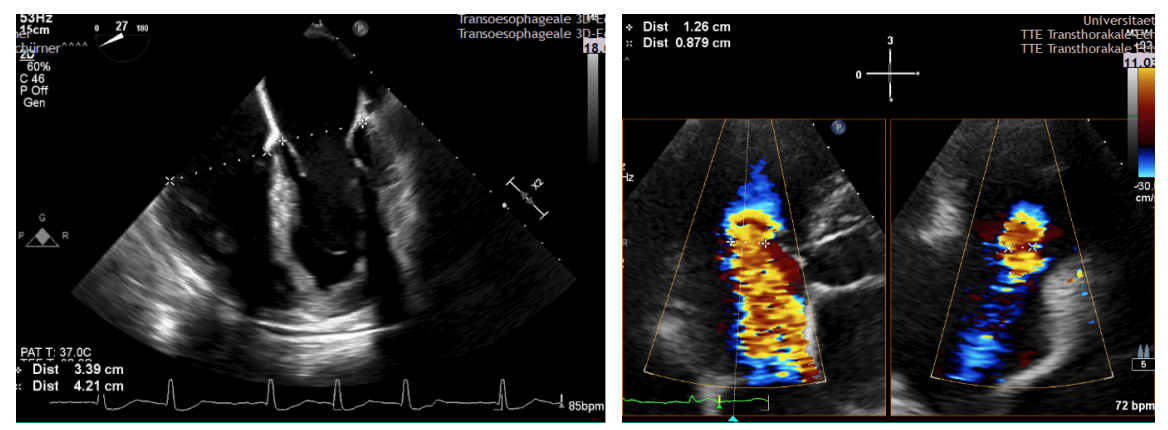

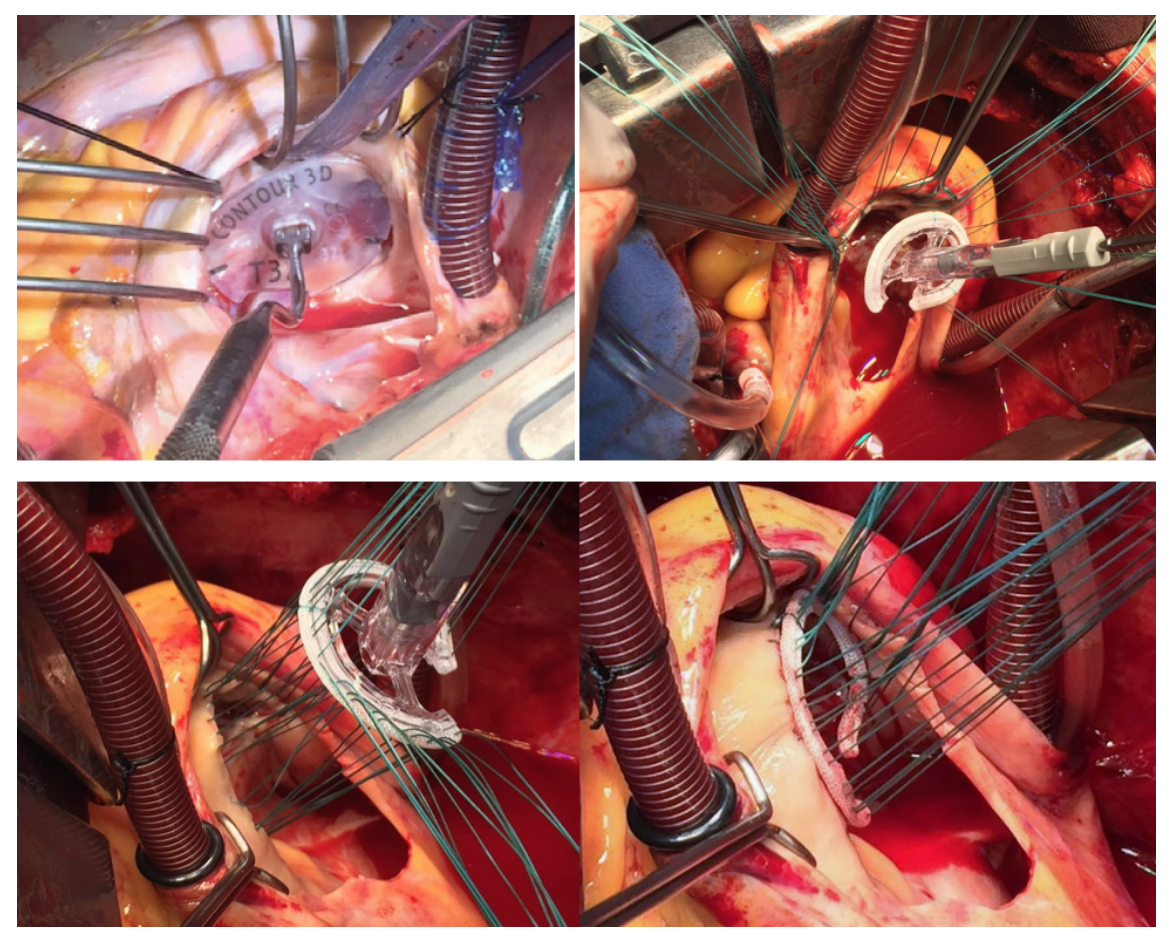


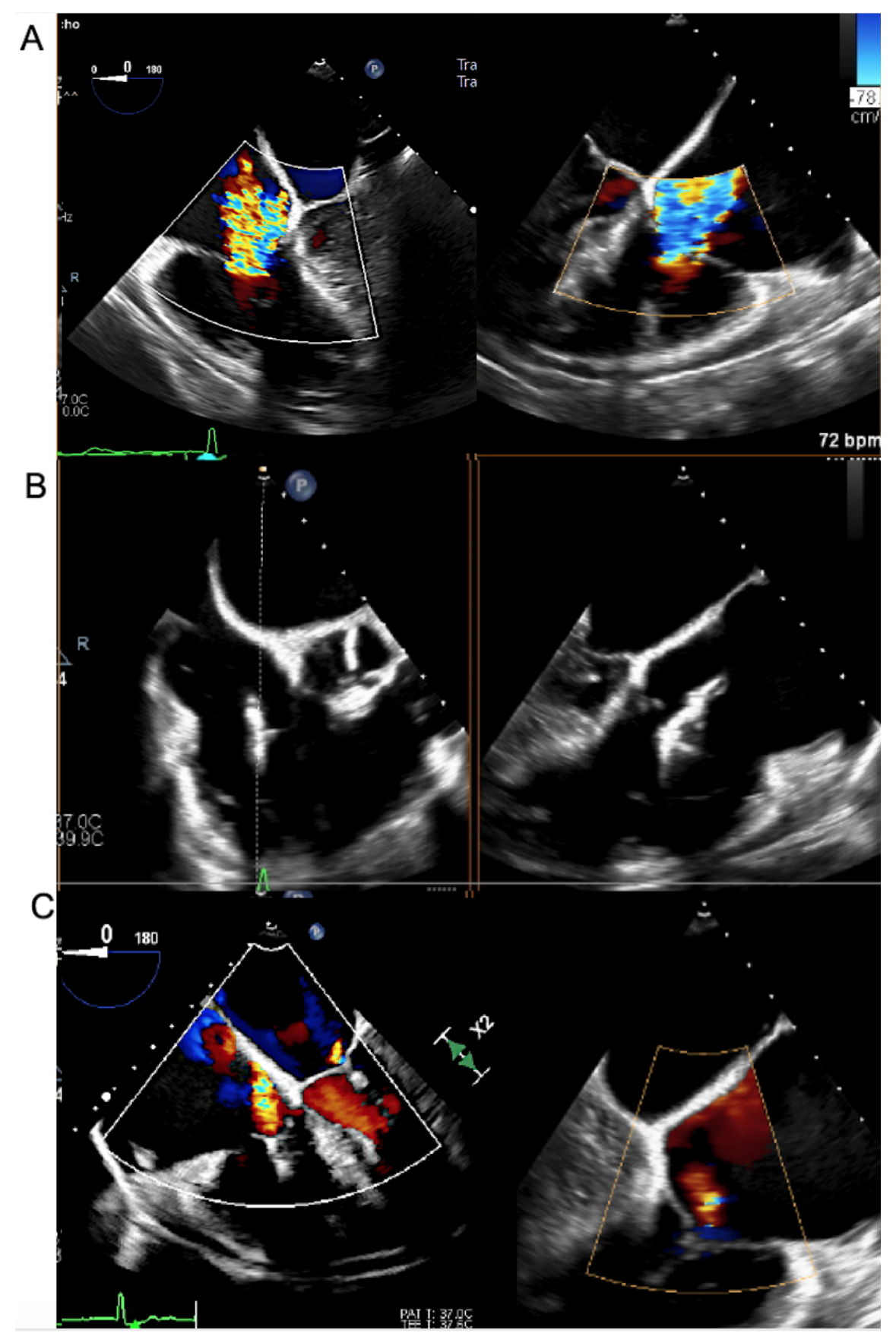

